\title{
A Corrosion Detection Method for Steel Strands Based on LC Electromagnetic Resonance
}

\author{
Yong Huang, ${ }^{1,2}$ Hang Zhang, ${ }^{1}$ Benniu Zhang $\mathbb{D}^{1},{ }^{1}$ Xingxing Li, ${ }^{1}$ Xiaoyu Sang, \\ Yi Si, ${ }^{2}$ A. Pa Er, ${ }^{2}$ Yiwei Zheng, ${ }^{2}$ Qiang Yin, ${ }^{2}$ and Jianhui Jiang ${ }^{2}$ \\ ${ }^{1}$ Chongqing Jiaotong University, Chongqing 400074, China \\ ${ }^{2}$ Xinjiang Communications Construction Group Co., Ltd., Urumchi 830000, China
}

Correspondence should be addressed to Benniu Zhang; 990020030755@cqjtu.edu.cn

Received 13 March 2020; Accepted 20 April 2020; Published 11 May 2020

Academic Editor: Andrey E. Miroshnichenko

Copyright (C) 2020 Yong Huang et al. This is an open access article distributed under the Creative Commons Attribution License, which permits unrestricted use, distribution, and reproduction in any medium, provided the original work is properly cited.

\begin{abstract}
At present, prestress detection is a worldwide problem. Corrosion has an important impact on the accuracy of the stress detection results of prestressed tendons. Once the steel strands in service is corroded, stress corrosion will occur, which seriously affects the safe operation of the prestressed structure. Based on the LC electromagnetic resonance circuit to detect the prestressing force of steel strands, this research has been successfully applied to the detection of the corrosion rate of steel strands, which lays the foundation for the nondestructive detection of the healthy state of steel strands in the existing structure. In this study, the steel strands were regarded as an external inductor embedded in the LC resonance circuit. After the steel strands was corroded, its electromagnetic characteristics would change, and this change was manifested by the resonance frequency. In this paper, the regular change of the resonance frequency caused by the change of the inductance of the steel wire after corrosion was explained theoretically, and a theoretical model of the relationship between the electromagnetic resonance frequency and the corrosion rate was established. In this study, it was proved through experiments that the LC electromagnetic resonance method can accurately detect the overall corrosion degree of bare steel stranded wires, and a fitting formula for corrosion detection of steel stranded wires was established. Through the analysis and exploration of the test data and test phenomena, it has been found that the action mechanism of the stranded wire decreases with the increase of the corrosion rate and the inductance thereof, which leads to the increase of the resonance frequency. The discovery of these laws will provide an improved basis for the prestress detection of inservice steel strands by LC resonant circuits and make the method to be further applied to practical engineering.
\end{abstract}

\section{Introduction}

Prestressed structure has the characteristics of reducing structural cracks and improving the bearing capacity of the structure. But a long time working in a complex environment will lead to the corrosion of prestressed reinforcement in prestressed bridge; under the action of stress, the steel strands is prone to stress corrosion, which will have a very adverse impact on the safety of the structure. Therefore, it is very important to find out the corrosion condition of the prestressed steel strands in the bridge [1-5].

At present, acoustic emission, stress wave, and ultrasonic wave are the common methods to detect corrosion of prestressed tendons. Huo et al. use a piezoelectric ceramic transducer to linearly correlate the peak value of the stress wave with the times reversal operation of the stress wave, indicating the feasibility of using time reversal to monitor the corrosion of steel bars [6]. Cheng et al. [7] uses the new noncontact capacitive sensor to measure the thickness of various steel rust layers. This method is more sensitive to larger diameter steel bars and has a higher volume expansion ratio. Climent et al. [8] found that when the microcracks in the steel bars are caused by corrosion, the ultrasonic excitation of a sudden center frequency is accompanied by the generation of higher harmonics in the output signal. Sriramadasu et al. [9] continuously monitors the corrosion state 
of steel bars in concrete beams by generating and receiving ultrasonic guided waves from piezoelectric wafer sensors attached to the steel bars. At the same time, Sriramadasu et al. [10] also used the ultrasonic guided wave to detect the wave packet of the corrosion center of the steel bar and used the two different wave packets to propose the damage index method, which can be successfully used to monitor the pitting degree and strength of the steel bar.

K. Reichling and M. Raupac $\beta 1$ [11] developed the German anode ladder system, which uniformly has six single anodes in different depths in concrete. This method can be used to judge whether the steel bar is corroded based on the resistance change, macro current change, or potential change generated when the steel is corroded. Yang et al. [12] introduced the metal magnetic memory technology into the rust detection of the steel inside the concrete and located the rust area according to the magnetic field change information on the surface of the rusted test piece and at the same time semiquantitatively evaluated the degree of corrosion. The use of the improved half-cell potential method in China to detect corrosion of concrete poles can, to a certain extent, eliminate the interference of external factors on the rust potential and accurately reflect the corrosion information of steel inside the concrete [13]. Gao et al. [14] designed the MCD steel corrosion detection sensor. The test results show that the absolute error of the measured corrosion rate and the true value of the sensor is less than $1 \%$, which can truly represent the corrosion degree of the steel. At the same time, Jin et al. [15] will use the MCD sensor built-in reinforced concrete beam. The accelerated corrosion test shows that the time-varying curve of the calculated corrosion rate of the sensor can reflect the dynamic change of steel corrosion in concrete.

At present, the team has achieved some results in the previous research of nondestructive testing of prestressed steel strands based on LC electromagnetic resonance circuit. Zhang et al. [16-18] proved that steel stranded wires have good electromagnetic characteristics in LC resonant circuits and established a theoretical model between the resonance frequency and stress of steel stranded wires. It has been verified through experiments that the detection method can accurately detect the stress of the steel strands, and the effect of the length of the steel strands on the resonance frequency was established $[19,20]$.

At present, the detection of effective prestress in structures is still a worldwide problem, and there is no mature and accurate method for nondestructive testing of effective prestress in active prestressed structures. The main reason for this problem is the state and environment of steel strands in the structure. This analysis of environmental effects on the prestress detection of steel strands is essential. On the basis of the above research, the researchers carried out testing of steel strands closer to the actual engineering status. In this study, the steel strands under no stress was corroded. It has been experimentally analyzed that the resonance frequency $f$ of steel strands will increase with the increase of its corrosion rate $\eta$. In the theoretical derivation process and analysis of experimental data, it was found that the reason for the above rule is that the inductance of the steel strands will decrease with the increase of the corrosion rate. At the same time, the laws discovered in this article will be applied to the research of LC electromagnetic resonance circuit in the prestress detection, which will make the application of the method of the laboratory to the actual engineering one step further. Compared with other corrosion detection methods, detecting the corrosion rate of steel strands using the LC electromagnetic resonance circuit is simpler, more convenient, and less expensive. Moreover, this method can simultaneously detect the prestress of the steel strands. The researchers believe that this method will provide a new way for the accurate detection of the health state of prestressed tendons in the existing structure.

\section{Theoretical Model}

2.1. Detection Principle of LC Resonant Circuit. The LC circuit is also called a resonance circuit or a tuning circuit. The circuit is connected by an inductor $L$ and a capacitor $C$. In the resonant circuit designed in this test, a steel stranded wire was used as a substitute for the original inductance, and an external fixed capacitor element was used to form an LC oscillation circuit, as shown in Figure 1.

We can know from electromagnetic theory, assuming that the LC resonant circuit resonates without any energy loss, the inductive reactance $X_{L}$ exhibited by the inductor $L$ of the oscillating circuit is equal to the capacitive reactance $X_{C}$ exhibited by the capacitor $C$ :

$$
X_{L}=X_{C}
$$

The expression of the inductance $X_{L}$ and inductance $X_{C}$ of the capacitor can be expressed as follows:

$$
\begin{aligned}
& X_{L}=2 \pi f L, \\
& X_{C}=\frac{1}{2 \pi f C} .
\end{aligned}
$$

where $f$ is the oscillation frequency of the LC resonance circuit, $L$ is the inductance of the steel strands, and $C$ is the fixed capacitance in the circuit.

Therefore, the simultaneous formulas (1)-(3) can be used to obtain the relationship between the resonant frequency $f$ and the inductance $L$ of a steel strands wire as the inductance of an LC resonant circuit:

$$
2 \pi f L=\frac{1}{2 \pi f C} \text {. }
$$

The following formula can be obtained by sorting formula (4):

$$
f=\frac{1}{2 \pi \sqrt{\mathrm{LC}}}
$$

2.2. Corrosion Detection Principle of Steel Strands Based on Electromagnetic Resonance. The steel strands in practical engineering application is a structure formed by twisting 7 strands of steel wire, and each steel wire will become a spiral 


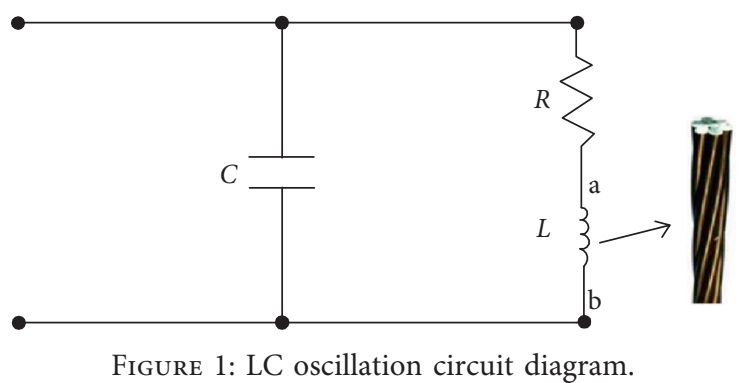

structure. Therefore, in the study, we regarded the steel strands as a spiral coil (as shown in Figure 2).

When the steel strand is regarded as a spiral coil, its inductance is as follows:

$$
L=\frac{\mu_{0} \mu_{r} N^{2} S}{l},
$$

where $L$ is the inductance of a straight section of a straight wire, $N$ is the spiral coil turns, $l$ is the strand length, $S$ is the wire cross-sectional area, $\mu_{0}$ is the vacuum permeability, and $\mu_{\mathrm{r}}$ is the relative magnetic permeability of ferromagnetic materials.

According to the analysis of formula (5), it can be known that the magnitude of the resonance frequency $f$ is affected by the magnitude of the inductance $L$ in the resonance circuit. It can be seen from formula (6) that the inductance $L$ of the steel strands is related to its cross-sectional area $S$ and length $l$. Because the length of the stranded steel wire in the prestressed concrete structure after anchoring is unchanged during service, the effect of the length $l$ on the inductance $L$ is not considered. When it is assumed that the permeability of the steel strands does not change during corrosion, the inductance $L$ of the steel strands is only related to its sectional area $S$. So, we can correlate the cross section of the steel strands with the resonant frequency. The reduction amount of the cross-sectional area $S$ of the reinforcing bar is different under different corrosion rates, so different corrosion rates $\eta$ will cause different changes in the frequency of the strand.

According to GB/T50082-2009, the calculation of the corrosion rate is as follows:

$$
\eta=\frac{M_{1}-M_{2}}{M_{1}} \times 100 \%
$$

where $\eta$ is the average degree of corrosion of steel strands, $M_{1}$ is the quality of the original sample $(\mathrm{kg})$, and $M_{2}$ is the quality of the sample after corrosion $(\mathrm{kg})$.

Because the cross-sectional area of the corroded steel strands cannot be directly measured, the average crosssectional area is calculated by the amount of corrosion. The calculation formula is as follows:

Average cross section

$$
\bar{S}=S-\frac{10^{3}\left(M_{1}-M_{2}\right)}{D} .
$$

where $S$ is the nominal sectional area of original sample, $\mathrm{mm}^{2}$, and $D$ is the material density, $\mathrm{kg} / \mathrm{m}^{3}$.

The simultaneous formulas (7) and (8) are as follows:

$$
\bar{S}=S-\frac{10^{3} M_{1} \eta}{D} .
$$

Substituting formula (9) into formula (6), we get

$$
L=\frac{\mu_{0} \mu_{r} N^{2}\left(S D-10^{3} \times \eta M_{1}\right)}{D l} .
$$

Formula (11) is obtained by combining formula (10) and formula (5):

$$
\eta=\frac{S D}{10^{3} \times M_{1}}-\frac{D l}{4 \times 10^{3} \times \pi^{2} \mu_{0} \mu_{r} f^{2} c M_{1} N^{2}} .
$$

In formula (11), it can be seen that the corrosion rates $\eta$ and $f$ in the resonance circuit of the prestressed steel strands as an inductor show a proportional relationship. We will verify this relationship in later experiments.

\section{Experiments}

In this test, all 1860 steel strands with a length of $1 \mathrm{~m}$ and a diameter of $15.2 \mathrm{~mm}$ were used for accelerated electrochemical corrosion. Corroded steel stranded wire is used as the inductance element in the LC electromagnetic resonance circuit to connect the circuit, and the relationship between the corrosion rate and the resonance frequency is detected. According to the specification GB/T5224-2014, the characteristics of the steel strands are shown in Table 1.

3.1. LC Electromagnetic Resonance Detection System. The MC1648 oscillation chip is used in the electromagnetic oscillation circuit in this device. The signal conditioning module and voltage comparator chip use LM393. Figure 3 shows the schematic diagram of the $\mathrm{LC}$ resonance circuit. $L_{1}$ is the steel strands connected to the oscillating circuit at both ends, $C_{1}, C_{2}$ are the power supply filter capacitors, $C_{3}$ is the input filter capacitor, $C_{4}$ is the resonance capacitor, and $R_{1}$ is the matching resistor.

Working principle of LC resonant circuit: with capacitor in the circuit as energy storage element, the inductor begins to charge when the capacitor begins to discharge; when the capacitor is discharged, the inductor is fully charged and the voltage in the inductor reaches the maximum value and the electric field energy in the capacitor is all converted into the magnetic field energy in the inductance coil. After that, the 


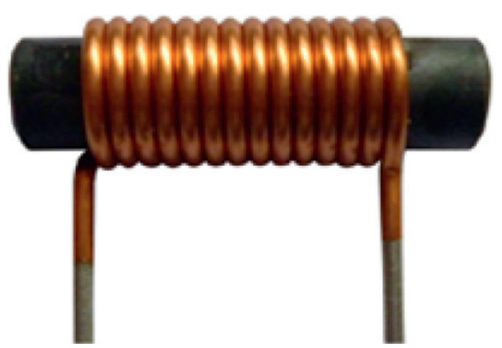

(a)

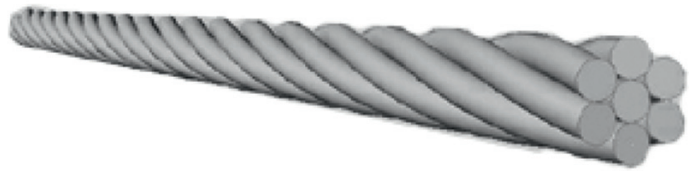

(b)

Figure 2: Comparison of inductance coil and prestressed steel hinged wire structure.

TABLE 1: Steel strand parameters.

\begin{tabular}{|c|c|c|c|c|c|}
\hline Structure & $\begin{array}{l}\text { Nominal diameter } \\
(\mathrm{mm})\end{array}$ & $\begin{array}{l}\text { Cross-sectional area } \\
\left(\mathrm{mm}^{2}\right)\end{array}$ & $\begin{array}{l}\text { Intensity level } \\
(\mathrm{MPa})\end{array}$ & $\begin{array}{c}\text { Maximum load of the entire steel } \\
\text { strands }(\mathrm{kN})\end{array}$ & $\begin{array}{l}\text { Elongation } \\
(\%)\end{array}$ \\
\hline $\begin{array}{l}1 \times 7 \text { standard } \\
\text { type }\end{array}$ & 15.2 & 140 & 1860 & 260 & 3.5 \\
\hline
\end{tabular}

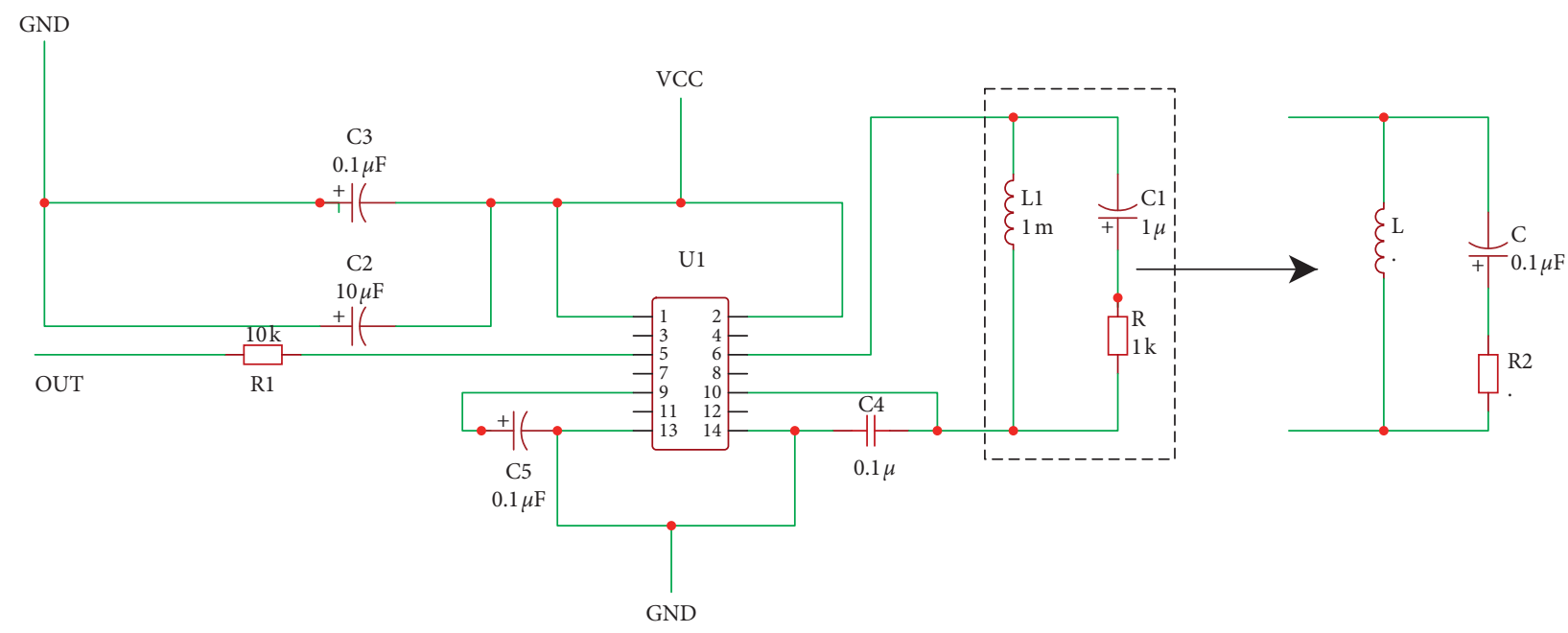

FIGURE 3: LC resonant circuit schematic.

inductance $L_{1}$ starts to discharge and the capacitor $C_{1}$ is gradually charged. When the capacitor voltage reaches the maximum, the charging is completed and the inductor is discharged. At this time, the magnetic field energy of the inductive coil is completely converted into the electric field energy in the capacitor. The circuit will be cycle repeated in accordance with the above process, and an oscillating current appears in the circuit. This periodic change in electric and magnetic fields is called electromagnetic oscillation; in the process of electromagnetic oscillation, the electric energy stored in the capacitor $C_{1}$ and the magnetic energy stored in the inductance coil $L_{1}$ are continuously converted to each other.

3.2. Construction of Electrochemical Corrosion System. The electrochemical corrosion device used in this test is shown in Figure 4. From the diagram, it can be seen that the

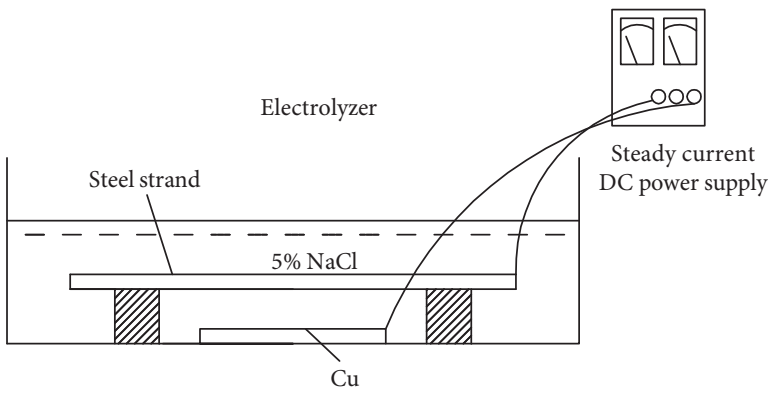

FIGURE 4: Electrochemical corrosion device.

positive pole of the regulated DC power supply is connected to the steel strands. The steel strands and the conductor are welded to ensure the stability of the connection between them. Solder the lead connected to the negative electrode to the copper plate in the corrosion tank. Due to the smooth 
surface of the copper plate, punch the edges of the copper plate before welding. This way can ensure good electrical conductivity between the copper plate and the conductor during the corrosion process.

At the same time, the device is equipped with a $2.5 \%$ $\mathrm{NaCl}$ solution as the electrolyte of the device. [21] verified that the corrosion rate was the highest in the $\mathrm{NaCl}$ solution with a concentration of $2.5 \%$ when accelerating corroded the reinforcement in the laboratory.

3.3. Test Process. Before this test, 18 prestressed steel strands with a length of $1 \mathrm{~m}$ were intercepted. $2.5 \% \mathrm{NaCl}$ solution is prepared and placed in the test tank (and).

(1) All steel strands shall be numbered, and each 3 steel strands shall be divided into one group and 6 groups in total. The grouping is shown in Table 2 .

(2) Before each group of steel wire is corroded, the LC resonant circuit is used to detect and record the frequency data detected within one minute and take the average value. Each group of steel strand is placed on an electronic scale and weighed to take the average $M_{1}$.

(3) The electrochemical corrosion device is connected, the weighed steel stranded wire is placed in the corrosion tank, and the stabilized DC power supply is used for corrosion (Figure 5).

(4) After that, the steel strands are taken out every 10 hours for cleaning, rust removal, and drying, and then an electronic scale is used to weigh and record the average mass $M_{2}$;

(5) The rusted steel strands are connected to the resonance circuit for detection, and the resonance frequency measured in one minute is recorded and the average value is taken.

(6) Repeat the above test steps.

In the corrosion test shown in Figure 5, the researchers accelerated the corrosion of the stranded wires in parallel. In [22], it is proved that, in the electrochemical accelerated corrosion test, the parallel connection corrosion method is more effective. Figure 6 shows how the LC electromagnetic resonance detection system works. After the power supply, the LC electromagnetic resonance circuit will input the electromagnetic signal to the steel strands and the frequency meter in the system displays the frequency data on the frequency meter after detecting the resonance frequency of the steel strands and transmits the resonance frequency to the computer through Bluetooth for data processing.

3.4. Test Data. Each group of 3 prestressed steel strands with a length of $1 \mathrm{~m}$ was placed in an electrochemical corrosion device, the resonance frequency was measured every 10 hours, and the average data were recorded as shown in Tables 3-8.
In these six sets of test data, the researchers performed a frequency test of 1 minute on each strand and took the average value as the resonance frequency of this strand test. Although the length of each strand is the same, there may be differences in the strands, so in order to test the accuracy of the data, the frequency data of each group of 3 strands is averaged.

\section{Experimental Results and Data Analysis}

4.1. Data Analysis. The average values of the real average corrosion rate and resonance frequency of the steel strand in the six groups of test data are counted in Table 9 and plotted in the same diagram, as shown in Figure 7. It can be seen that the data from six experiments show the same law. That is, the corrosion rate of steel strands has a positive correlation with the square of its resonance frequency. The above phenomenon is in accordance with the relationship between the corrosion rate of the steel strands and the square of the resonance frequency as shown in formula (11). This proves that the theoretical relationship between the corrosion rate of steel strands and the resonance frequency derived in 2.2 is correct. Through data analysis and Figure 8, the following conclusions can be drawn.

(1) As the corrosion rate $\eta$ of the steel strands increases, the resonance frequency $f$ obtained by the LC resonance circuit will increase accordingly. It can be obtained that there is a quadratic relationship between the corrosion rate $\eta$ and the resonance frequency $f$.

(2) From the conclusion (1) and formula (5), we can see that the increase in resonance frequency must be caused by the decrease in inductance. From the inductance formula (10) derived in Section 2.2, it can be seen that the increase in the corrosion rate of the steel strands causes its inductance $L$ to decrease. An analysis of the true corrosion rate and resonance frequency of the steel strands reveals that there is a certain relationship between the increase in the resonance frequency of the strand $\Delta f$ and the increase in the corrosion rate $\Delta \eta$.

(3) Table 10 lists the variation of the resonance frequency for each $1 \%$ increase in the corrosion rate of the steel strands. Therefore, the researchers believe that when the $1 \mathrm{~m}$ long stranded steel wire is placed in the LC resonant circuit for detection, the frequency changes by $1.40 \mathrm{kHz}$ and its corrosion rate increases by $1 \%$. However, whether there is a similar relationship among other lengths of steel strands needs to be verified by further tests.

Fit and process the six sets of test data (as shown in Figure 8 ) are used to obtain the fitting formula:

$$
\eta^{\prime}=1.821 \times 10^{-5} f^{2}-2.495 \text {. }
$$


TABLE 2: Steel strand grouping table.

\begin{tabular}{lccc}
\hline Classification & & Number of steel strands \\
\hline First group & 1 & 2 & 3 \\
Second group & 4 & 5 & 6 \\
Third group & 7 & 11 & 9 \\
Fourth group & 10 & 14 & 12 \\
Fifth group & 13 & 17 & 15 \\
Sixth group & 16 & 18 \\
\hline
\end{tabular}

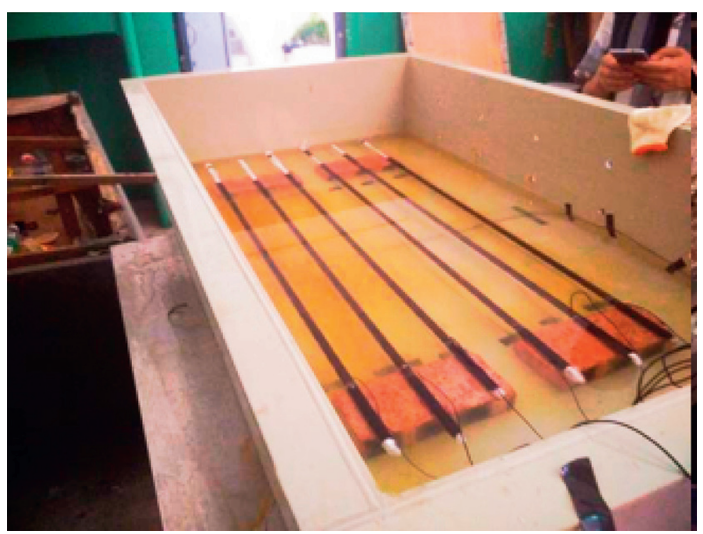

FIGURE 5: Corrosion diagram of steel strands.

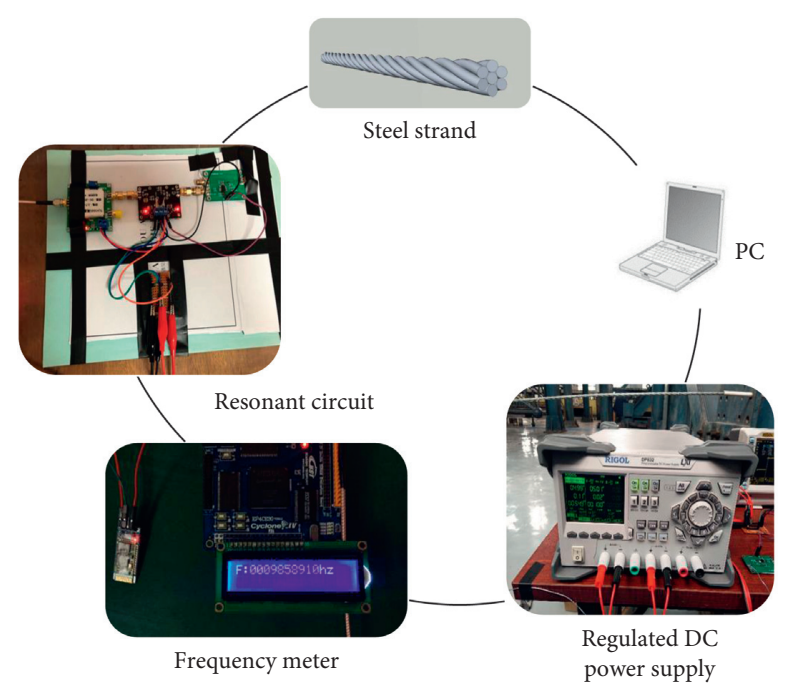

Figure 6: LC electromagnetic resonance detection system detection diagram.

Taking formula (12) as the core formula of the LC electromagnetic resonance circuit detection system, the calculation result of this formula is regarded as the detection corrosion rate of the steel strands detected by this testing system.

4.2. Error Analysis. Compare the detected rust rate obtained from the LC electromagnetic resonance system tested with the real rust rate in Table 11.
At the same time, the standard error corresponding to each test was calculated. In order to facilitate data comparison, the measured corrosion rate and the actual corrosion rate calculated by the fitting formula are plotted in Figure 9. From the chart, we can see that the detected corrosion rate is smaller than the true corrosion rate, which shows that there is a certain error in the detection results. The smaller standard deviation value in Table 11 indicates that the deviation of each test data is smaller. After careful 
TABle 3: Test data of the first group of steel strands.

\begin{tabular}{|c|c|c|c|c|c|c|c|}
\hline \multicolumn{3}{|c|}{ True rust rate $(\%)$} & \multirow[b]{2}{*}{$\begin{array}{l}\text { Average true rust rate } \\
(\%)\end{array}$} & \multicolumn{3}{|c|}{ Resonant frequency $f(\mathrm{kHz})$} & \multirow{2}{*}{$\begin{array}{l}\text { Average frequency } \\
(\mathrm{kHz})\end{array}$} \\
\hline $\begin{array}{l}\text { Steel strands } \\
1\end{array}$ & $\begin{array}{c}\text { Steel strands } \\
2\end{array}$ & $\begin{array}{c}\text { Steel strands } \\
3\end{array}$ & & $\begin{array}{c}\text { Steel strands } \\
1\end{array}$ & $\begin{array}{c}\text { Steel strands } \\
2\end{array}$ & $\begin{array}{c}\text { Steel strands } \\
3\end{array}$ & \\
\hline 0 & 0 & 0 & 0 & 371.234 & 370.263 & 368.959 & 370.152 \\
\hline 2.06 & 2.11 & 2.13 & 2.1 & 371.124 & 372.532 & 371.129 & 371.595 \\
\hline 4.01 & 3.98 & 4.16 & 4.05 & 372.896 & 373.124 & 373.091 & 373.037 \\
\hline 6.33 & 6.45 & 6.42 & 6.4 & 375.122 & 374.864 & 373.454 & 374.48 \\
\hline 7.92 & 7.93 & 7.94 & 7.93 & 376.113 & 376.023 & 375.633 & 375.923 \\
\hline 10.30 & 10.37 & 10.31 & 10.34 & 377.210 & 376.981 & 377.904 & 377.365 \\
\hline 12.45 & 12.72 & 12.63 & 12.6 & 378.684 & 379.022 & 378.789 & 378.808 \\
\hline
\end{tabular}

TABLE 4: Test data of the second group of steel strands.

\begin{tabular}{|c|c|c|c|c|c|c|c|}
\hline \multicolumn{3}{|c|}{ True rust rate $(\%)$} & \multirow{2}{*}{$\begin{array}{l}\text { Average true rust rate } \\
(\%)\end{array}$} & \multicolumn{3}{|c|}{ Resonant frequency $f(\mathrm{kHz})$} & \multirow{2}{*}{$\begin{array}{l}\text { Average frequency } \\
(\mathrm{kHz})\end{array}$} \\
\hline $\begin{array}{l}\text { Steel strands } \\
4\end{array}$ & $\begin{array}{c}\text { Steel strands } \\
5\end{array}$ & $\begin{array}{c}\text { Steel strands } \\
6\end{array}$ & & $\begin{array}{c}\text { Steel strands } \\
4\end{array}$ & $\begin{array}{c}\text { Steel strands } \\
5\end{array}$ & $\begin{array}{c}\text { Steel strands } \\
6\end{array}$ & \\
\hline 0 & 0 & 0 & 0 & 371.104 & 370.383 & 368.405 & 369.964 \\
\hline 1.97 & 2.07 & 2.26 & 2.1 & 370.994 & 372.652 & 370.575 & 371.407 \\
\hline 3.97 & 3.94 & 3.76 & 3.89 & 372.766 & 373.244 & 372.537 & 372.849 \\
\hline 6.29 & 6.41 & 5 & 5.9 & 374.992 & 374.984 & 372.9 & 374.292 \\
\hline 7.88 & 7.89 & 8.83 & 8.2 & 375.983 & 376.143 & 375.079 & 375.735 \\
\hline 10.26 & 10.33 & 9.02 & 9.87 & 377.08 & 377.101 & 377.35 & 377.177 \\
\hline 12.41 & 12.68 & 10.7 & 11.93 & 378.554 & 379.142 & 378.164 & 378.62 \\
\hline
\end{tabular}

TABle 5: Test data of the third group of steel strands.

\begin{tabular}{|c|c|c|c|c|c|c|c|}
\hline \multicolumn{3}{|c|}{ True rust rate $(\%)$} & \multirow[b]{2}{*}{$\begin{array}{l}\text { Average true rust rate } \\
(\%)\end{array}$} & \multicolumn{3}{|c|}{ Resonant frequency $f(\mathrm{kHz})$} & \multirow{2}{*}{$\begin{array}{l}\text { Average frequency } \\
(\mathrm{kHz})\end{array}$} \\
\hline $\begin{array}{l}\text { Steel strands } \\
7\end{array}$ & $\begin{array}{c}\text { Steel strands } \\
8 \\
\end{array}$ & $\begin{array}{c}\text { Steel strands } \\
9\end{array}$ & & $\begin{array}{c}\text { Steel strands } \\
7\end{array}$ & $\begin{array}{c}\text { Steel strands } \\
8 \\
\end{array}$ & $\begin{array}{c}\text { Steel strands } \\
9\end{array}$ & \\
\hline 0 & 0 & 0 & 0 & 371.144 & 370.143 & 369.676 & 370.321 \\
\hline 1.93 & 2.11 & 2.38 & 2.14 & 371.034 & 372.412 & 371.846 & 371.764 \\
\hline 3.93 & 3.98 & 4.72 & 4.21 & 372.806 & 373.004 & 373.808 & 373.206 \\
\hline 6.25 & 6.45 & 5.6 & 6.1 & 375.032 & 374.744 & 374.171 & 374.649 \\
\hline 7.84 & 7.93 & 8.17 & 7.98 & 376.023 & 375.903 & 376.35 & 376.092 \\
\hline 10.22 & 10.37 & 8.21 & 9.6 & 377.12 & 376.861 & 378.024 & 377.335 \\
\hline 12.37 & 12.72 & 11.81 & 12.3 & 378.594 & 378.902 & 379.435 & 378.977 \\
\hline
\end{tabular}

TABLE 6: Test data of the fourth group of steel strands.

\begin{tabular}{|c|c|c|c|c|c|c|c|}
\hline \multicolumn{3}{|c|}{ True rust rate $(\%)$} & \multirow{2}{*}{$\begin{array}{l}\text { Average true rust rate } \\
(\%)\end{array}$} & \multicolumn{3}{|c|}{ Resonant frequency $f(\mathrm{kHz})$} & \multirow{2}{*}{$\begin{array}{l}\text { Average frequency } \\
(\mathrm{kHz})\end{array}$} \\
\hline $\begin{array}{l}\text { Steel strands } \\
10\end{array}$ & $\begin{array}{c}\text { Steel strands } \\
11\end{array}$ & $\begin{array}{c}\text { Steel strands } \\
12\end{array}$ & & $\begin{array}{c}\text { Steel strands } \\
10\end{array}$ & $\begin{array}{c}\text { Steel strands } \\
11\end{array}$ & $\begin{array}{c}\text { Steel strands } \\
12\end{array}$ & \\
\hline 0 & 0 & 0 & 0 & 371.044 & 370.193 & 370.317 & 370.518 \\
\hline 2.01 & 1.99 & 2.18 & 2.06 & 370.934 & 372.462 & 372.787 & 372.061 \\
\hline 4.01 & 3.86 & 5.03 & 4.3 & 372.706 & 373.054 & 374.749 & 373.503 \\
\hline 6.33 & 6.33 & 4.14 & 5.6 & 374.932 & 374.794 & 374.212 & 374.646 \\
\hline 7.92 & 7.81 & 7.67 & 7.8 & 375.923 & 375.953 & 376.391 & 376.089 \\
\hline 10.3 & 10.25 & 8.73 & 9.76 & 377.02 & 376.911 & 379.562 & 377.831 \\
\hline 12.45 & 12.6 & 9.63 & 11.56 & 378.494 & 378.952 & 380.376 & 379.274 \\
\hline
\end{tabular}


TABLE 7: Test data of the fifth group of steel strands.

\begin{tabular}{|c|c|c|c|c|c|c|c|}
\hline \multicolumn{3}{|c|}{ True rust rate $(\%)$} & \multirow[b]{2}{*}{$\begin{array}{l}\text { Average true rust rate } \\
(\%)\end{array}$} & \multicolumn{3}{|c|}{ Resonant frequency $f(\mathrm{kHz})$} & \multirow{2}{*}{$\begin{array}{l}\text { Average frequency } \\
(\mathrm{kHz})\end{array}$} \\
\hline $\begin{array}{l}\text { Steel strands } \\
10\end{array}$ & $\begin{array}{c}\text { Steel strands } \\
11\end{array}$ & $\begin{array}{c}\text { Steel strands } \\
12\end{array}$ & & $\begin{array}{c}\text { Steel strands } \\
10\end{array}$ & $\begin{array}{c}\text { Steel strands } \\
11\end{array}$ & $\begin{array}{c}\text { Steel strands } \\
12\end{array}$ & \\
\hline 0 & 0 & 0 & 0 & 371.044 & 370.193 & 370.317 & 370.518 \\
\hline 2.01 & 1.99 & 2.18 & 2.06 & 370.934 & 372.462 & 372.787 & 372.061 \\
\hline 4.01 & 3.86 & 5.03 & 4.3 & 372.706 & 373.054 & 374.749 & 373.503 \\
\hline 6.33 & 6.33 & 4.14 & 5.6 & 374.932 & 374.794 & 374.212 & 374.646 \\
\hline 7.92 & 7.81 & 7.67 & 7.8 & 375.923 & 375.953 & 376.391 & 376.089 \\
\hline 10.3 & 10.25 & 8.73 & 9.76 & 377.02 & 376.911 & 379.562 & 377.831 \\
\hline 12.45 & 12.6 & 9.63 & 11.56 & 378.494 & 378.952 & 380.376 & 379.274 \\
\hline
\end{tabular}

TABLE 8: Test data of the sixth group of steel strands.

\begin{tabular}{|c|c|c|c|c|c|c|c|}
\hline \multicolumn{3}{|c|}{ True rust rate $(\%)$} & \multirow[b]{2}{*}{$\begin{array}{l}\text { Average true rust rate } \\
(\%)\end{array}$} & \multicolumn{3}{|c|}{ Resonant frequency $f(\mathrm{kHz})$} & \multirow{2}{*}{$\begin{array}{l}\text { Average frequency } \\
(\mathrm{kHz})\end{array}$} \\
\hline $\begin{array}{l}\text { Steel strands } \\
16\end{array}$ & $\begin{array}{c}\text { Steel strands } \\
17\end{array}$ & $\begin{array}{c}\text { Steel strands } \\
18\end{array}$ & & $\begin{array}{c}\text { Steel strands } \\
16\end{array}$ & $\begin{array}{c}\text { Steel strands } \\
17\end{array}$ & $\begin{array}{c}\text { Steel strands } \\
18\end{array}$ & \\
\hline 0 & 0 & 0 & 0 & 371.024 & 370.433 & 368.384 & 369.947 \\
\hline 1.85 & 1.89 & 1.66 & 1.8 & 370.914 & 372.702 & 370.554 & 371.390 \\
\hline 3.85 & 3.76 & 3.79 & 3.8 & 372.686 & 373.294 & 372.516 & 372.832 \\
\hline 6.17 & 6.23 & 5 & 5.8 & 374.912 & 375.034 & 372.879 & 374.275 \\
\hline 7.76 & 7.71 & 7.93 & 7.8 & 375.903 & 376.193 & 375.058 & 375.718 \\
\hline 10.14 & 10.15 & 10.01 & 10.1 & 377 & 377.151 & 377.329 & 377.160 \\
\hline 12.29 & 12.5 & 11.39 & 12.06 & 378.474 & 379.192 & 378.143 & 378.603 \\
\hline
\end{tabular}

analysis and comparison of the data in Table 11 and Figure 9, we can get a new conclusion (4):

(4) From the results, the reason that the true corrosion rate is higher than the calculated corrosion rate is probably due to the corresponding change in the magnetic permeability of the steel strands under the effect of corrosion. It can be seen from formula (11) that the calculation of the lower corrosion rate may be due to the decreases in the magnetic permeability of the steel strands after corrosion. That is, the magnetic permeability $\mu$ of the steel strands will decrease as the corrosion rate $\eta$ increases.

From the direct comparison of the corrosion rate of the 42 test groups and the actual corrosion rate, it can be seen that the difference between the corrosion rates of the two groups is only over $1 \%$. Significance analysis of 6 groups of test data at 0.05 significance levels and the analysis data are given in Table 12. It can be seen from Table 12 that the sum of squared residuals for the six trials is small, and the larger $R^{2}$ in the table proves that the regression effect of the fitting formula is better. From the results of the significance test, it can be seen that the test results are more reliable.

According to the above analysis, there is a certain error in the detection of the corrosion rate, and the main reasons for the error are as follows:

(1) In formula (6), the researchers only considered the influence of the change in the cross-sectional area $S$ of the steel strands on the inductance $L$ after corrosion, the influence of corrosion on the magnetic permeability of steel strands is not considered. The main reason for not considering the permeability is that the permeability is greatly affected by the environment, and secondly, there is no simple and accurate method to detect the permeability.

(2) Although researchers try to maintain the stability of the environment during the test, due to the high sensitivity of the LC electromagnetic resonance detection system, the device is greatly affected by the external environment and the test results will inevitably be affected by external factors.

(3) The frequency drifts may also be the cause of the error. The error of the frequency of the steel strands detected in the LC electromagnetic resonance system will cause the accumulation of errors due to the influence of the frequency drift.

\section{Conclusions and Prospects}

In this paper, the electromagnetic resonance detection system uses the steel strands as the external inductance, and the change in the inductance characteristics of the steel strands after corrosion is displayed in the form of a resonance frequency. From Section 2.2, it can be known that the change of the cross-sectional area of the steel strands after corrosion will cause the change of its inductance and then its resonance frequency. This process shows the causal relationship between the corrosion rate and the resonance frequency of the corroded steel wire as the external inductance in the LC electromagnetic resonance detection system. The experiment proves that the LC electromagnetic resonance method can effectively detect the overall 


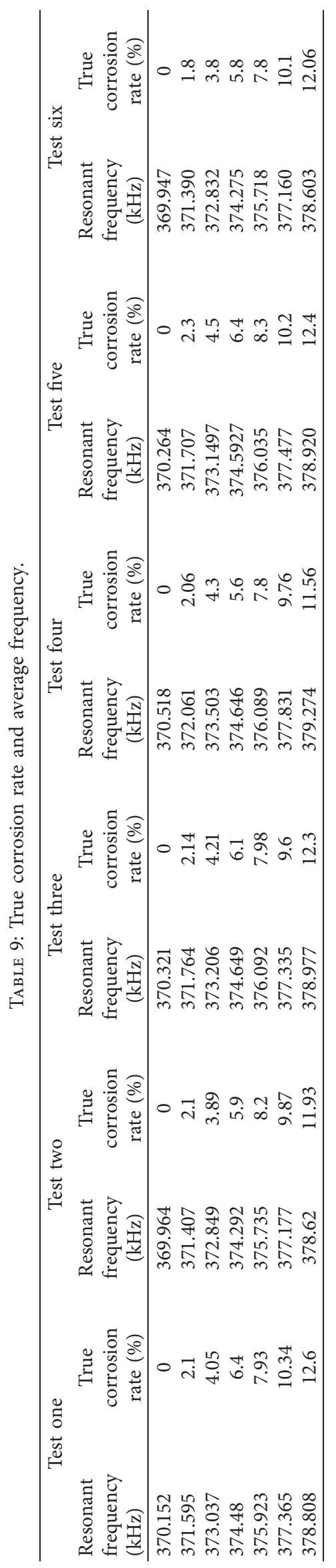




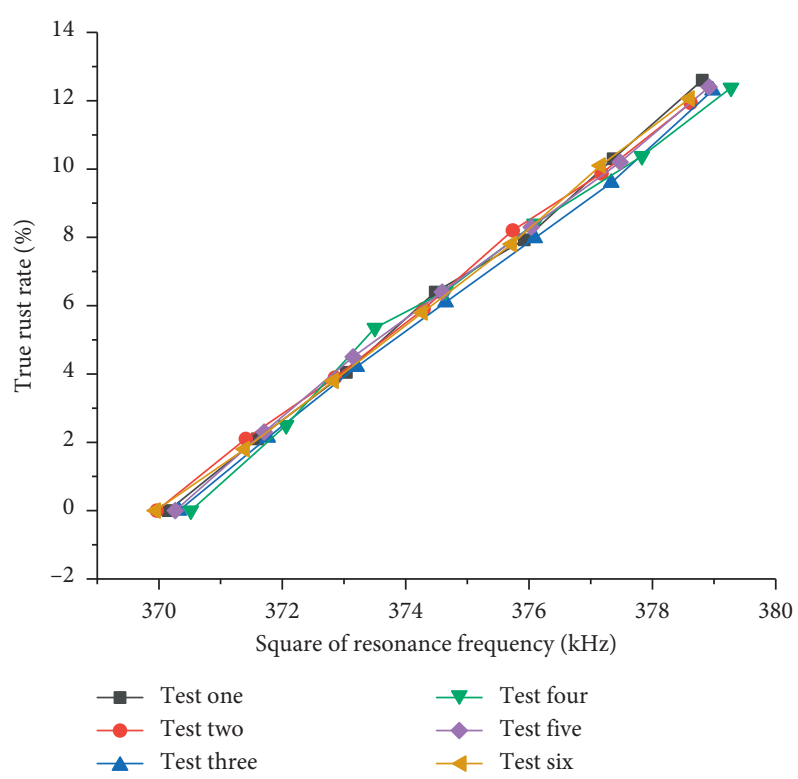

FIgURE 7: Relationship between square of resonance frequency and corrosion rate.

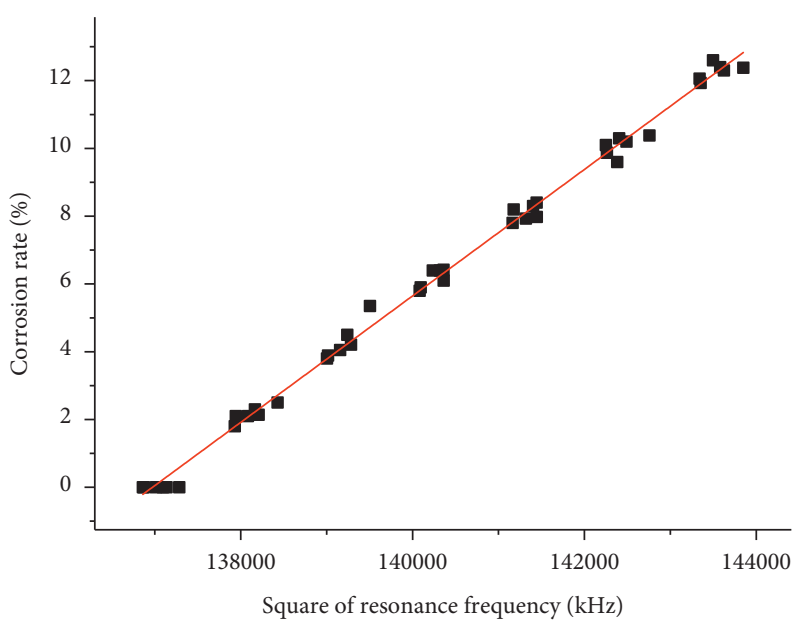

Figure 8: Data fitting diagram.

TABLE 10: Resonance frequency increment at unit corrosion rate.

\begin{tabular}{lccccccc}
\hline Numbering & Test one & Test two & Test three & Test four & Test five & Test six & Average value \\
\hline$\Delta f$ & 1.456 & 1.378 & 1.421 & 1.320 & 1.433 & 1.393 & 1.40 \\
\hline
\end{tabular}

corrosion degree of steel strands and provides a new method for corrosion detection of steel strands in prestressed structures.

After conducting electrochemical accelerated corrosion of steel stranded wire and connecting it to the LC resonance circuit experiment, we have reached the following conclusions:

(1) The resonance frequency of the steel strands detected by the LC resonance circuit has a positive correlation with the corrosion rate, the resonance frequency will increase with the increase of the corrosion rate, and the frequency change and the corrosion rate are characterized by a quadratic function relationship.

(2) The value of the inductance in the steel strands will decrease as its corrosion rate increases.

(3) The permeability of the steel strands decreases as the corrosion rate increases.

(4) When the length of $1 \mathrm{~m}$ steel stranded wire is placed in the LC resonant circuit, the corrosion rate increases by $1 \%$ for every $1.40 \mathrm{kHz}$ frequency change. 


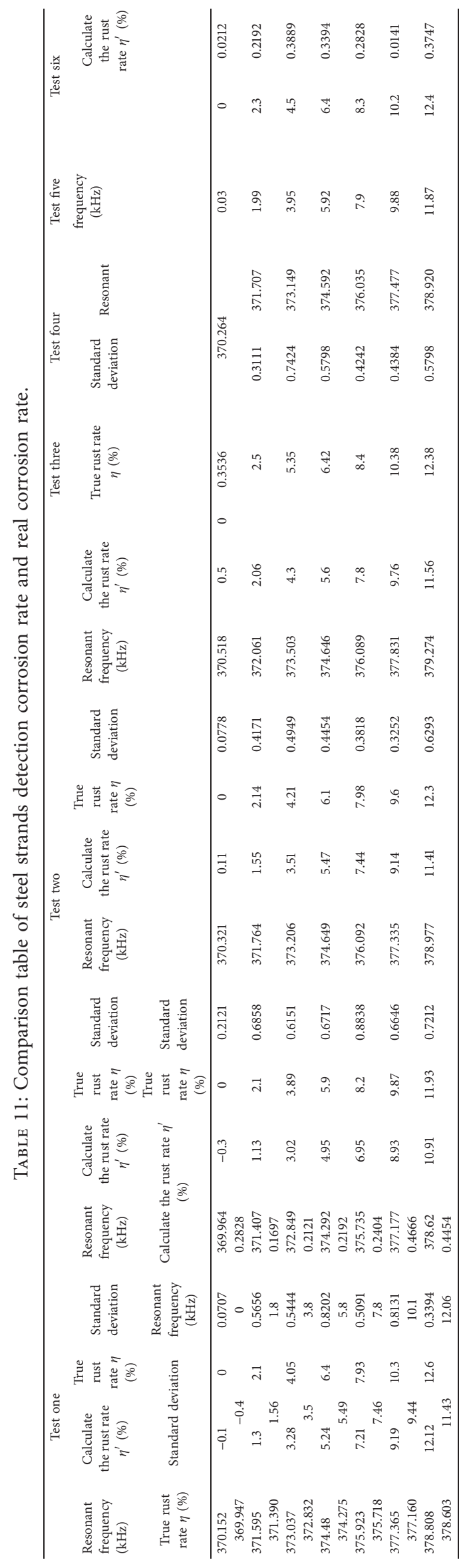




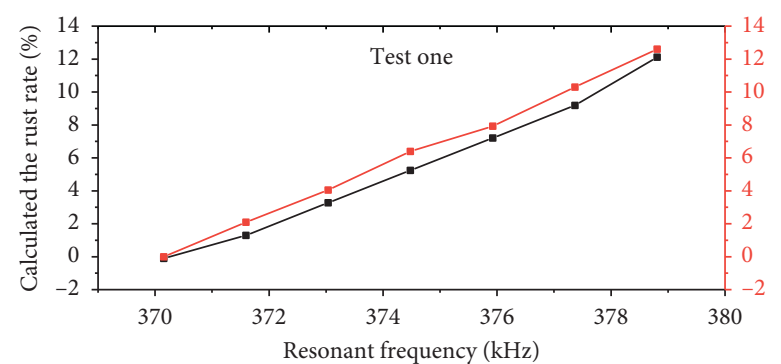

- Calculate the rust rate

$\rightarrow$ True rust rate

(a)

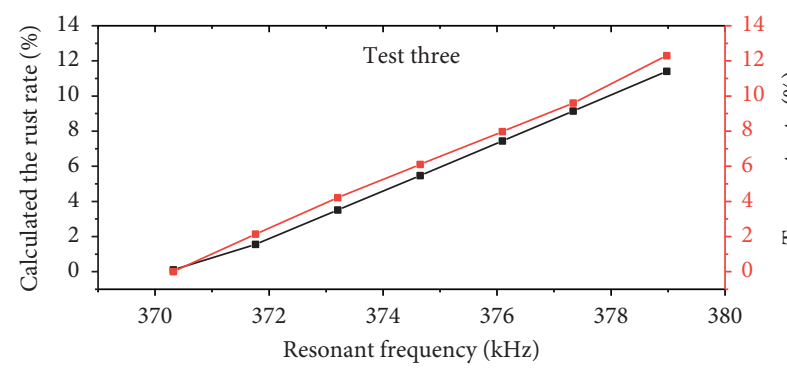

- Calculate the rust rate

- True rust rate

(c)

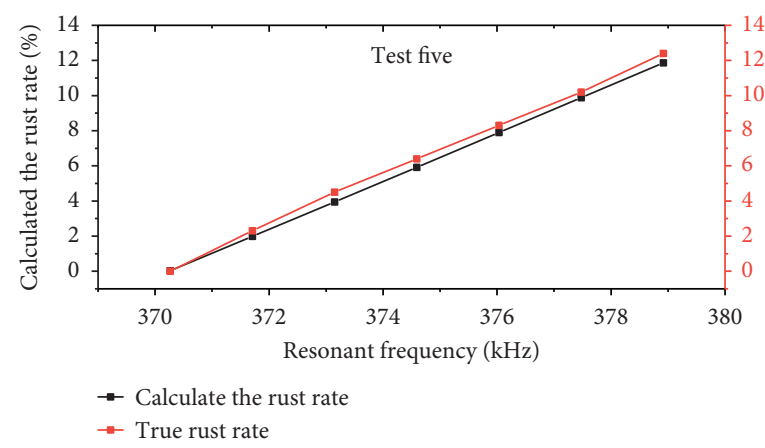

(e)

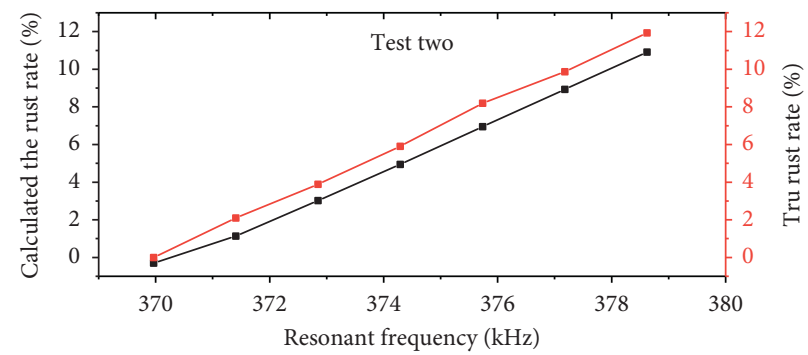

$\rightarrow$ Calculate the rust rate

$\rightarrow$ Tru rust rate

(b)

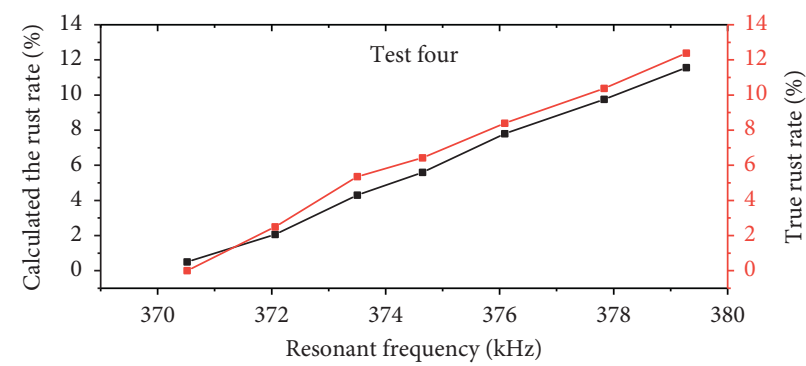

- Calculate the rust rate

- True rust rate

(d)

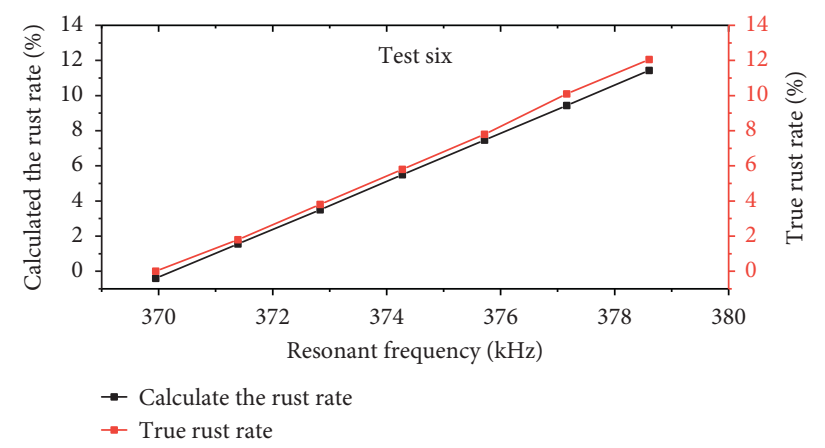

(f)

Figure 9: Comparison between calculated corrosion rate and real corrosion rate.

TABLE 12: Reliability analysis of measuring corrosion rate.

\begin{tabular}{lcccc}
\hline Test number & Sum of residuals & $R^{2}$ & Significant test value $|t|$ & Significant level \\
\hline Test one & 0.19851 & 0.99803 & 55.16149 & Significant \\
Test two & 0.08707 & 0.99906 & 79.68127 & Significant \\
Test three & 0.12596 & 0.99863 & 66.2417 & Significant \\
Test four & 0.1923 & 0.99775 & 51.6377 & Significant \\
Test five & 0.29552 & 0.99686 & 43.68697 & Significant \\
Test six & 0.09359 & 0.99903 & 78.43202 & Significant \\
\hline
\end{tabular}

Note: the significance level $\alpha=0.05$, the number of curve points per sample is $7, n=7$; critical $t$ value: $t \alpha / 2(n-2)=2.5706$.

Although the team has made some progress in the prestress detection using the system in the early stage, the detection of corrosion of steel strands based on LC electromagnetic resonance circuits is still in its infancy. In the future research, we will carry out the detection of the corrosion of steel strands in the structure The research lays the foundation for the system to accurately detect the stress state and corrosion state of the prestressed tendons in the prestressed structure in the future.

\section{Data Availability}

The data used to support the findings of this research work are included within the article. 


\section{Conflicts of Interest}

The authors declare no conflicts of interest.

\section{Acknowledgments}

This research was funded by the National Key Research and Development Program of China, grant number 2017YFC0806007, the Program for Innovation Team Building at Institutions of Higher Education in Chongqing, grant number CXTDG201602013, the Technology Innovation Project of Chongqing Social Undertakings and People's Livelihood, grant number CSTC2016SHMSZX30026, the Urumqi Science and Technology Plan, grant number Y161320008, and the key technology research project "construction of extra high pier T-shaped bridge in high strength and high altitude area" from Xinjiang Communications Construction Group Co., Ltd.

\section{References}

[1] E. Chen and C. K. Y. Leung, "A coupled diffusion-mechanical model with boundary element method to predict concrete cover cracking due to steel corrosion," Corrosion Science, vol. 126, pp. 180-196, 2017.

[2] E. Chen and C. K. Y. Leung, "Finite element modeling of concrete cover cracking due to non-uniform steel corrosion," Engineering Fracture Mechanics, vol. 134, pp. 61-78, 2015.

[3] W. Zhu, R. François, Q. Fang, and D. Zhang, "Influence of long-term chloride diffusion in concrete and the resulting corrosion of reinforcement on the serviceability of RC beams," Cement and Concrete Composites, vol. 71, pp. 144$152,2016$.

[4] A. Barrias, J. Casas, and S. Villalba, "A review of distributed optical fiber sensors for civil engineering applications," Sensors, vol. 16, no. 5, p. 748, 2016.

[5] C. S. Rajeshwara, S. Banerjee, and Y. Lu, "Identification of zero effect state in corroded RCC structures using guided waves and embedded piezoelectric wafer transducers (PWT)," Procedia Engineering, vol. 188, pp. 209-216, 2017.

[6] L. Huo, C. Li, T. Jiang, and H.-N. Li, "Feasibility study of steel bar corrosion monitoring using a piezoceramic transducer enabled time reversal method," Applied Sciences, vol. 8, no. 11, p. 2304, 2018.

[7] Y. Cheng, A. Hanif, E. Chen, G. Ma, and Z. Li, "Simulation of a novel capacitive sensor for rebar corrosion detection," Construction and Building Materials, vol. 174, p. 174, 2018.

[8] M. Climent, M. Miró, J. Carbajo, P. Poveda, G. de Vera, and J. Ramis, "Use of non-linear ultrasonic techniques to detect cracks due to steel corrosion in reinforced concrete structures," Materials, vol. 12, no. 5, p. 813, 2019.

[9] R. C. Sriramadasu, Y. Lu, and S. Banerjee, "Identification of incipient pitting corrosion in reinforced concrete structures using guided waves and piezoelectric wafer transducers," Structural Health Monitoring, vol. 18, no. 1, pp. 164-171, 2018.

[10] R. C. Sriramadasu, S. Banerjee, and Y. Lu, "Detection and assessment of pitting corrosion in rebars using scattering of ultrasonic guided waves," NDT \& E International, vol. 101, pp. 53-61, 2019.

[11] K. Reichling and M. Raupach, "Method to determine electrochemical potential gradients without reinforcement connection in concrete structures," Cement and Concrete Composites, vol. 47, pp. 3-8, 2014.
[12] M. Yang, J. Zhou, and H. Zhang, "Magnetic memory detection of steel corrosion inside concrete," Journal of Building Materials, vol. 2, pp. 345-350, 2018.

[13] W. Li, J. Guo, and X. Li, "Improved half-cell potential method to test the degree of corrosion of concrete poles," Green Building Materials, vol. 4, pp. 227-228, 2019.

[14] R. Gao, N. Jin, and Ye Tian, "Application of magnetic medium theory in the detection of steel corrosion," Low Temperature Building Technology, vol. 41, pp. 1-7, 2019.

[15] N. Jin, R. Gao, Ye Tian, X. Jin, and Z. Li, "Design and application of MCD steel corrosion detector," Journal of Building Materials, vol. 5, pp. 1-13, 2019.

[16] D. Chen, B. Zhang, X. Li et al., "A stress measurement method for steel strands based on LC oscillation," Advances in Materials Science and Engineering, vol. 2018, Article ID 1584903, 8 pages, 2018.

[17] X. Li, B. Zhang, C. Yuan et al., "An electromagnetic oscillation method for stress measurement of steel strands," Measurement, vol. 125, pp. 330-335, 2018.

[18] B. Zhang, C. Yuan, Z. Chen, and X. Li, "Stress measurement of steel strands based on LC oscillation," Journal of Chongqing Jiaotong University, vol. 36, pp. 8-12, 2017.

[19] B. Zhang, C. Tu, X. Li, H. Cui, and G. Zheng, "Length effect on the stress detection of prestressed steel strands based on electromagnetic oscillation method," Sensors, vol. 19, no. 12, p. 2782, 2019.

[20] B. Zhang, Y. Zhao, X. Li, Y. Su, Q. Yin, and J. Jiang, "Study on the main factors of frequency variation of LC resonant prestress detection method," Advances in Materials Science and Engineering, vol. 2020, Article ID 9526843, 10 pages, 2020.

[21] X. Chen and X. Wang, "Test methods and parameters for accelerated corrosion of reinforced bars with different compositions in concrete," Materials Protection, vol. 47, pp. 45-46, 2014.

[22] Y. Zeng, X. Gu, and W. Zhang, "Discussion on accelerated corrosion method of steel bars in concrete," Structural Engineer, vol. 25, pp. 101-105, 2009. 